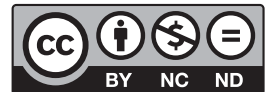

Estudos Teológicos foi licenciado com uma Licença Creative Commons Atribuição - NãoComercial - SemDerivados 3.0 Não Adaptada

http://dx.doi.org/10.22351/et.v60i1.3737

\title{
Origem, transmissão e significado das Cartas do CéU (HIMMELSBRIEFE) $)^{1}$
}

Origin, transmission and meaning of Letters of Heaven (Himmelsbriefe)

\section{Scheila Roberta Janke²}

Resumo: As assim chamadas Cartas do Céu ou Cartas de Proteção foram trazidas por imigrantes europeus ao Brasil e se tornaram importantes fontes de fé para eles e seus descendentes na superação de dificuldades, já que garantiam às pessoas que as portassem proteção contra todos os perigos que pudessem lhes afetar no corpo e na alma. Apesar de criticadas como fonte de superstição pela igreja durante séculos, a tradição literária das Cartas do Céu só pode ter surgido, se desenvolvido e sido propagada dentro do âmbito eclesial. O acesso a fontes primárias - como exemplares da Carta do Céu encontrados em arquivos e bibliotecas na Alemanha e também entre descendentes de imigrantes pomeranos no Brasil - bem como a estudos do historiador da religião Rudolf Stübe e de outros especialistas no assunto permite a reconstrução do conteúdo e da história traditiva dessas cartas. Esse será o propósito deste artigo. Por fim, com base em um dos exemplares encontrados em Pelotas (RS), será possível fazer uma análise do seu conteúdo e das diferentes partes, originalmente independentes, que lhe foram acrescentadas para aumentar sua suposta eficácia.

Palavras-chave: Revelação divina. Tradição religiosa. Fórmulas mágicas e conteúdo bíblico. Eficácia. Proteção.

Abstract: The so-called Letters from Heaven or Letters of Protection were brought by European immigrants to Brazil and became important sources of faith for them and their descendants in overcoming difficulties, since they guaranteed people to protect them against all dangers that could affect them in body and soul. Although criticized as a source of superstition by the Church for centuries, the literary tradition of the Letters from Heaven can only have arisen, developed and been propagated within the ecclesial sphere. Access to primary sources - such as copies of the Letters from Heaven found in archives and libraries in Germany and also among descendants of Pomeranian immigrants in Brazil -, as well as the studies of religion historian Rudolf Stübe and other subject matter experts, allows the reconstruction of the content and the traditional history of these letters. This will be the purpose of this article. Finally, based on one of

1 O artigo foi recebido em 04 de julho de 2019 e aprovado em 07 de novembro de 2019 com base nas avaliações dos pareceristas ad hoc.

2 Doutora em Teologia. FATEV. E-mail: scheilajanke@gmail.com 
the copies found in Pelotas (RS), it will be possible to make an analysis of its content and the different parts, originally independent, that have been added to increase its supposed effectiveness.

Keywords: Divine revelation. Religious tradition. Magical formulas and biblical content. Effectiveness. Protection.

\section{Introdução}

Durante séculos reinou grande mistério em torno das assim chamadas Cartas do Céu (Himmelsbriefe). Imigrantes europeus as trouxeram consigo para o Brasil e as multiplicaram para seus descendentes. Eles costumavam trazê-las junto ao corpo, penduravam-nas nas paredes ou colocavam-nas nos sótãos de suas casas, pois acreditavam que essas cartas teriam o poder de protegê-los de doenças, armas e perigos, mas também proteger suas casas, animais e plantações de catástrofes naturais e pragas. Principalmente nos primeiros anos de colonização, quando os imigrantes e seus descendentes viviam isolados na mata, sem acesso a hospitais, médicos e parteiras, e travavam conflitos armados com populações indígenas que habitavam as áreas destinadas pelo governo brasileiro à colonização, as Cartas do Céu adquiriram grande importância. Mas também diante de revoltas (Movimento dos Mucker, 1868-1874), revoluções (Guerra dos Farrapos, 1835-1845, e a Revolução Federalista, 1893-1895) e guerras (Guerra contra as províncias da Argentina, 1825-1828; do Uruguai, 18641865; do Paraguai, 1864-1870; Primeira e Segunda Guerras Mundiais, 1914-1918 e 1939-1945 respectivamente), as Cartas do Céu mais uma vez lhes conferiram a sensação de possuir um objeto concreto que os protegesse contra todos os tipos de perigos a que estivessem sujeitos.

A antropóloga Joana Bahia, em sua pesquisa de campo com descendentes pomeranos no Espírito Santo, entendeu que nas Cartas do Céu um agricultor dialogava com Deus. ${ }^{3}$ No entanto, uma pesquisa por fontes primárias revela uma origem totalmente diferente, como veremos a seguir.

\section{Origem e história traditiva das Cartas do Céu}

Para descobrir a partir de que momento já se fazia menção a Cartas do Céu e como se deu sua transmissão ao longo dos séculos, os estudos de Stübe, Dieterich e Beckert \& Nail são de grande importância.

A Carta do Céu é mencionada já no século VI d.C. De acordo com a lenda, ela teria originalmente caído do céu nas proximidades de lugares considerados sagrados ou em igrejas. O exemplar original, ainda segundo a lenda, teria sido escrito com letras douradas por um anjo, geralmente o anjo Miguel. Diferentes exemplares da carta encontrados entre descendentes de imigrantes europeus no Espírito Santo, Santa Ca-

3 BAHIA, Joana. O tiro da bruxa. Rio de Janeiro: Garamond, 2001. p. 357. 
tarina e Rio Grande do Sul ainda fazem referência a essa lenda sobre o aparecimento da carta e oferecem com isso uma indicação sobre seu estilo literário: uma revelação escrita de Deus. A noção antropomórfica de deuses que se revelam aos seres humanos por meio de mensagens escritas já estava presente em povos antigos que portavam sistemas de escrita. Isso leva a concluir que a tradição literária da revelação divina por meio da escrita provenha originalmente do Egito, da Babilônia ou da China. Tudo leva a crer, porém, que a tradição da Carta do Céu tenha se originado no Egito e de lá tenha sido assumida também pelo helenismo. ${ }^{4}$ A tradição da Carta do Céu ainda estaria, segundo Stübe, presente no Talmude judeu, na Cabala medieval, na seita judeu-cristã dos Elcasaítas (século II d.C.), nos Odes de Salomão, nos Atos gnósticos de Tomás, no Pastor de Hermas (em torno de 130 d.C.), no livro apócrifo Saga de Agar (século III d.C.), na Antiguidade, na filosofia, na mística, no islã, no Livro dos Mórmons, em legendas cristãs e também na tradição bíblica. ${ }^{5}$ Por causa disso, as Cartas do Céu chegaram a ser classificadas de pseudoepígrafes e apócrifos cristãos. ${ }^{6}$

De acordo com Stübe, a forma mais antiga da Carta do Céu seria a assim chamada Carta de Domingo (Sonntagsbrief). Ela teria sido escrita por Jesus Cristo e caído sobre o altar da Catedral de São Pedro em Roma e exigia a rigorosa observância do domingo como dia de descanso. A menção mais antiga dessa carta é feita no ano de 584 ou 585 d.C. na ilha espanhola Ibiza, quando o bispo Vincêncio a teria lido em uma missa e enviado uma cópia ao bispo Liciniano em Cartago. Esse rejeitou a carta como heresia por considerá-la uma tentativa de introduzir o Sabbat judaico na igreja. ${ }^{7}$

No ano de 321 o imperador Constantino (306-337) instituiu o domingo como dia oficial de descanso no império. Essa disposição logo foi introduzida também na Gália e assumida na legislação franca, o que leva a crer que a Carta de Domingo teria surgido no Reino Franco. Nesse território ela também teria encontrado terreno fértil para sua disseminação diante das ameaças de um destino terrível para as pessoas que descumprissem o descanso dominical. ${ }^{8}$

Apesar de a Carta de Domingo ter sido condenada por um sínodo em Roma no ano de 745, nada pôde conter sua disseminação, nem mesmo entre o clero. Devido às relações entre as igrejas anglo-saxã e irlandês-escocesa, monges intermediaram a chegada da carta até a Inglaterra no fim do século VIII ou início do século IX. No século X ela já era conhecida também na Islândia. Com a migração dos povos na Europa Ocidental, a carta recebeu uma nova redação na Inglaterra ou na Irlanda em torno do

4 STÜBE, R. Der Himmelsbrief. Tübingen: Mohr (Paul Siebeck), 1918. p. 30; STÜBE, R. Himmelsbrief. In: HOFFMAN-KRAYER, E.; BÄCHTOLD-STÄUBLI, Hanns (Hrg.). Handwörterbuch des Deutschen Aberglaubens. [Dicionário de superstição alemã]. Berlin; Leipzig: Walter de Gruyter, 1931/1932. v. 4, p. 22s.

5 STÜBE, R. Himmelsbrief, 1931/1932, p. 23-25; STÜBE, 1918, p. 31-42.

6 BECKERT, Hans Günther; NAIL, Norbert. Der alte Gasthof zum Schützenpfuhl in Marburg. Mit einem Beitrag über „Himmelsbrief“. [A antiga pousada “Zum Schützenpfuhl” em Marburgo. Com uma contribuição sobre a "Carta do Céu"]. Marburg: Magistrat der Stadt Marburg, 2008. p. 131.

7 STÜBE, 1918, p. 12s; STÜBE, R. Sonntagsbrief. In: HOFFMAN-KRAYER, E.; BÄCHTOLD-STÄUBLI, Hanns (Hrg.). Handwörterbuch des Deutschen Aberglaubens. [Dicionário de superstição alemã]. Berlin; Leipzig: Walter de Gruyter, 1936/1937. v. 8, p. 99s.

8 STÜBE, 1918, p. 15; STÜBE, Sonntagsbrief, 1936/1937, p. 100s. 
ano de 850. Entre os séculos IX e XV ela se espalhou pela Itália, Espanha, França, Alemanha, Áustria e Boêmia. Outras variações da carta surgiram a partir de uma terceira redação, que aconteceu durante sua disseminação no leste europeu e alcançou os povos eslavos, romenos e gregos. ${ }^{9}$ A partir desse momento a Carta do Céu se multiplicou mediante inúmeras cópias à mão ou impressas, tendo um alcance universal.

No século XIII a Carta de Domingo já estava disseminada na Alemanha. Um exemplar foi inclusive retrabalhado para a língua alemã como discurso para a penitência dos fiéis. Em torno do ano de 1260 a Carta do Céu também adquiriu grande importância na Alemanha e na Itália devido ao pânico apocalíptico e escatológico provocado pelos discursos de Joaquim de Fiore, anunciando a vinda do Anticristo e o início do Reino do Espírito Santo. Na mesma época a Europa sofria com o surto da peste. Esse fator, aliado ao conflito entre o imperador e o papa aumentaram a expectativa pelo fim do mundo na população. Flagelantes desfilavam pelas ruas e se flagelavam ao som de hinos de penitência em suas peregrinações. De acordo com Stübe, um dentre esses hinos de penitência seria um exemplar da terceira redação da Carta do Céu. ${ }^{10}$

A Carta do Céu voltou a adquirir maior atenção na metade do século XIV. A profetisa Brigitta (1303-1373) enviou um exemplar da carta ao papa Clemente VI (1342-1352) por ocasião dos debates contra a secularização da igreja. No livro intitulado Liber de reformatione monasteriorum, do superior geral da ordem agostiniana João Busch, por sua vez, é mencionada uma Carta de Proteção (Schutzbrief) atribuída ao papa Leo III (795-816). Um exemplar dessa carta foi encontrado no ano de 1451 em Halle, na Alemanha, com a esposa de um soldado. ${ }^{11}$

A Carta do Céu teria oferecido ainda, segundo Röhrich, a forma literária para escritos teológicos na época da Reforma, como, por exemplo, Cartas do Céu contra indulgências. ${ }^{12}$ Nicolaus Hermann (ca. 1500-1561) publicou no ano de 1524 uma prédica de penitência, que teria sido escrita pelo próprio Cristo como mandato aos seus fiéis cristãos. Contra o comércio de indulgências também o reformador Urbano

9 STÜBE, Sonntagsbrief, 1936/1937, p. 101s; STÜBE, 1918, p. 15-20. Pressupõe-se que exemplares da Carta do Céu existentes no Oriente em todas as suas recensões se originaram de um exemplar original grego ou copta, que não foi preservado. Desse exemplar também se originaram as traduções síria e armena. STÜBE, 1918, p. 25s. Segundo Dieterich, existem exemplares da Carta do Céu do tempo bizantino, que teriam surgido em Constantinopla ou Jerusalém. DIETERICH, Albrecht. Himmelsbrief. In: Blätter für Hessische Volkskunde [Folhas [Cadernos] sobre o folclore de Hessen], n. 3, ano III, 1901. p. 11. O filólogo oriental Bittner encontrou um exemplar da Carta do Céu num texto armênio do final do século I d.C., que teria pertencido a cristãos coptas. Veja BAUER, Wolfgang. Magisch-sympathetischer Hausschatz oder Die offenbarten Geheimnisse der natürlichen Magie nebst Zauberformeln, Heil-Sprüchen und Schutzsegen wider allerlei Anfechtungen. [Tesouro mágico-simpático ou Os segredos revelados da magia natural ao lado de fórmulas mágicas, ditos de cura e bênçãos de proteção contra todos os tipos de tentações]. In: 6./7. Buch Moses $\left[6^{\circ} / 7^{\circ}\right.$ Livro de Moisés]. Sein wahrer Wert und was das Volk darin sucht. [Seu verdadeiro valor e o que o povo procura nele]. Berlin: Karin Kramer, 1979. p. 207.

10 STÜBE, 1918, p. 21s.

11 Segundo Stübe, tratava-se da Carta ao rei Carlos (Kaiser Karl Brief) que o papa Leo III deveria entregar ao imperador Carlos o Grande (768-814) antes de sair para lutar na Batalha de Ronceval. STÜBE, 1918, p. 22s.

12 RÖHRICH, L. Himmelsbriefe. In: GALLING, Kurt et al. (Hrg.). Die Religion in Geschichte und Gegenwart. [A religião na história e no presente]. 3. Auflage, Tübingen: Mohr (Paul Siebeck), 1959. Band 3, p. 339. 
Rhegius (1489-1541) teria dirigido uma Carta do Céu em 1523. A Henrique Bullinger (1504-1575) é atribuído um escrito anônimo do ano de 1526 contendo uma Carta do Céu. No mesmo ano, Martim Lutero (1483-1546) publicou seu escrito Ob Kriegsleute auch im seligen Stande sein können, no qual ele lamenta que soldados benzessem cavalo e cavaleiro, conjurassem ferro e pedras, se encomendassem a São Jorge, São Cristóvão ou a algum outro santo e portassem consigo alguma coisa, na qual confiavam para se proteger de perigos. ${ }^{13}$ Stübe entende que aqui Lutero se refere a assim conhecida Bênção das [sobre as] armas (Waffensegen). Essa tem origem na tradição de sacerdotes, enquanto representantes de Deus, deuses ou poderes sobrenaturais, concederem a bênção a soldados que estavam indo para a batalha. Na época medieval também monges costumavam escrever bênçãos em pergaminhos que eram entregues a soldados como amuleto para protegê-los na guerra. ${ }^{14}$ Mais tarde representantes da igreja concederam sua bênção às tropas antes das batalhas, também sobre canhões, armamentos e até mesmo armas químicas. ${ }^{15}$ No século XV, com o avanço das técnicas militares e com a invenção da pólvora, as antigas fórmulas de bênção, como as conhecidas Bênção da [sobre a] espada (Schwertsegen), Bênção da bala (Kugelsegen) e Bênção das armas foram sendo gradativamente adaptadas a Cartas de Proteção e Cartas do Céu. Além disso, no século XVI, algumas Cartas de Proteção foram atribuídas ao papa Leo X (1513-1521) ou ao imperador Carlos V (1520-1556).

Mesmo com todas as proibições por parte da igreja e da conceituação pejorativa desses amuletos como superstição, essas fontes se multiplicaram principalmente na época da Guerra dos Trinta Anos (1618-1648), durante as batalhas na Revolução Francesa (1792-1802), nas Guerras de Libertação (1813-1815), na Guerra contra a Dinamarca (1864), na Guerra Austro-Prussiana (1866), na Guerra Franco-Prussiana (1870-1871), mas também durante a Primeira (1914-1918) e Segunda (1939-1945) Guerras Mundiais.

Apesar de as Cartas do Céu ou Cartas de Proteção nunca terem sido oficialmente reconhecidas como fonte de fé pela igreja, elas surgiram e se propagaram dentro do âmbito eclesial. De um lado, elas foram toleradas, em alguns casos até disseminadas pela igreja. De outro lado, elas foram proibidas, acusadas de heresia ou consideradas magia e superstição. Durante o século XV, por exemplo, elas foram proibidas sob a acusação de magia e às pessoas que portassem tal documento era negado o acesso ao sacramento. ${ }^{16}$ Já o papa Pio IX (1846-1878) teria permitido a impressão de Cartas do Céu e possibilitado que o editor Gustav Kühn as publicasse em folhetos com imagens. ${ }^{17}$ Sendo assim, na década de 1860, versões da Carta do Céu foram impressas por Gustav Kühn na cidade alemã de Neuruppin e logo surgiram em

\footnotetext{
13 LUTHER, Martin. Ob kriegsleutte auch ynn seligem stande seyn künden. [Se militares também podem estar em uma situação bem-aventurada]. In: D. Martin Luthers Werke [As obras de Martin Lutero]. Weimar: Böhlau, 1897. Band 19, p. 660.

${ }^{14}$ BAUER, Wolfgang. Was hat man von dem Volksglauben und der Volksmedizin zu halten? [O que podemos pensar sobre fé e medicina popular?] In: 6./7. Buch Moses. [6 $\%^{\circ}$ Livro de Moisés]. Sein wahrer Wert und was das Volk darin sucht. [Seu verdadeiro valor e o que o povo procura nele]. Berlin: Karin Kramer, 1979. p. 21.

15 BAUER, Magisch-sympathetischer Hausschatz, 1979, p. 202.

16 BAUER, Magisch-sympathetischer Hausschatz, 1979, p. 202.

17 Os assim conhecidos "Folhetos de imagens" de número 202 e 1.732. BECKERT; NAIL, 2008, p. 123.
} 
uma edição do assim chamado 6. und 7. Buch Mosis. ${ }^{18}$ As diferentes traduções, cópias e reformulações da carta durante os vários séculos de história traditiva fizeram com que seu conteúdo sofresse alterações. Algumas características específicas dos diferentes tipos de Carta do Céu, no entanto, ainda podem ser reconhecidas nos exemplares trazidos por imigrantes ao Brasil, como veremos a seguir.

\section{Análise de conteúdo de um exemplar da Carta do Céu encontrada entre imigrantes pomeranos no Brasil}

Uma análise detalhada de um dos exemplares da Carta do Céu encontrada entre descendentes de imigrantes pomeranos em Pelotas (RS) ${ }^{19}$ permite reconhecer elementos importantes para uma compreensão e interpretação de seu conteúdo, bem como os diferentes acréscimos feitos à Carta do Céu ao longo de sua história traditiva. Por esse motivo, ela será reproduzida em sua tradução do original em alemão:

Não digas tudo o que sabes.

Não creias em tudo que ouves.

Não julgues tudo o que vês.

Oh Deus, toda esta casa preserve,

de fogo, dano e perigo.

Com misericórdia e bênçãos esteja sobre nós,

e nos conserve em tua palavra pura.

Senhor Jesus, pelo teu nome, concede-me uma hora bem-aventurada; esteja junto a mim no último final.

Tome minha alma na sua mão.

Alegra-te de coração na fraqueza, essa é toda a perfeição.

É assim que acontece em todo tempo.

[Se] me amas, eu te faço sofrer,

[Se] me ajudas a levantar, eu te derrubo,

[Se] me honras grandemente, eu te desonro novamente.

Jesus Cristo é encontrado

na Palavra, que de Jesus se lê.

Jesus dá salvação e bem-aventurança

18 BAUER, Magisch-sympathetischer Hausschatz, 1979, p. 207.

${ }^{19}$ Himmels-Brief, wird genannt Credoria. [Carta do Céu, chamada Credoria]. Sem referência do local de impressão. 1 folha, 2 páginas. Fotografia. In: MALTZAHN, Gislaine Maria. Família, ritual e ciclos de vida. Estudo Etnográfico sobre narrativas pomeranas em Pelotas (RS). Pelotas: Universidade Federal de Pelotas, 2011. p. 141s. 
àquele que o serve todo o tempo.

Quem é consolado no nome de Jesus,

este é redimido por Jesus Cristo.

A Jesus, o querido filho,

ao amado Jesus,

sejam [dados] louvor e exaltação! Ó Jesus clemente,

proteja-nos sempre com teu escudo.

Dá-nos, Senhor Jesus, a tua graça.

Que mundo, diabo, morte não nos possam prejudicar!

Certa é a morte, incerto é o dia,

a hora ninguém pode saber.

Por isso confie em Deus e pense

que toda hora [pode] ser a última.

No sofrimento, tenha boa coragem.

E ama aquele que te faz sofrer.

Carta do Céu, chamada Credoria

A fim de que vocês se guardem de todo pecado, respeitem o feriado ${ }^{20}$ e vivam no temor de Deus, vocês alcançarão a eterna bem-aventurança. Mas se vocês não fizerem isso, eu irei puni-los com peste, fogo, fome, guerra e com o meu grave castigo. Eu irei lançar um rei contra o outro, um senhor contra o outro, a filha contra a mãe, um irmão contra o outro e depois tirarei a minha mão de vocês. Por causa da injustiça de vocês, eu vou pegar espadas de dois gumes e destruí-los, a seguir descerei sobre a terra com trovões e relâmpagos, para que vocês reconheçam minha ira e minha justiça divina, porque vocês trabalham no domingo. Devido ao amor paternal por vocês, eu os poupei até agora, senão vocês já teriam sido condenados há muito tempo por causa de sua injustiça; eu ordeno a vocês, tanto a jovens quanto a velhos, que frequentem diligentemente a igreja e se arrependam de seus pecados. Durante a penitência vocês não devem insultar seu próximo, [nem] antes [nem] depois, nem dar falso testemunho contra o seu próximo. Guardem-se da opressão aos pobres, mas ajudem os sedentos.

Quem não acredita nesta carta nunca deverá alcançar a bem-aventurança eterna, mas quem a levar consigo e a der a outros para ler, este poderá ter pecados sobre si como estrelas no céu ou grãos de areia no mar, assim lhe serão perdoados seus pecados; mas quem ouve 21 sobre esta carta, não a obtém e não a tem em sua casa, este não tem bênção. Quem, porém, não a der para ser lida ou copiada, este deve ser condenado. Por fim, eu lhes ordeno que guardem os meus mandamentos conforme Cristo os ensinou. Em nome de Deus Pai $†$, do filho de † e do Espírito Santo † Amém.

${ }^{20}$ Aqui se faz referência ao Domingo.

${ }^{21}$ No sentido de tomar conhecimento da carta. 


\section{- Quem leva esta bênção consigo -}

não sofrerá nenhum dano por um rifle carregado, porque estas são palavras que acentuam o divino e o que se [precisa] temer. Esta carta protege contra todo projétil, ladrões, inimigos e todos os inconvenientes. Através das seguintes palavras e do nome de nosso Senhor Jesus Cristo e com Deus, todas as queixas, espadas, rifles e todas as armas podem ser conjuradas;

1) Fiquem parados todos os fuzis visiveis e invisiveis, para que não me ataquem, pelo batismo de nosso Senhor Jesus Cristo, que foi batizado por João no rio Jordão.

2) Fiquem parados todos os fuzis visiveis e invisiveis, para que vocês não me ataquem, pelo comando do Espírito Santo.

3) Fiquem parados todos os fuzis visiveis e invisiveis, através do medo de nosso Senhor Jesus Cristo, que criou você e a mim.

4) Fiquem parados todos os fuzis e armas visiveis e invisiveis através do santo batismo daquele que morreu por nós. Mártir, como poderoso Deus, seja misericordioso para conosco! Em nome de Deus Pai, † e do Filho e do Espirito Santo † Amém.

Quem talvez não quiser atribuir fé as palavras mencionadas, este pode escrevê-las em um pedaço de papel e pendurá-las em volta do pescoço de um cachorro, depois atirar nele e ele não o atingirá. Em nome de Jesus, tão verdadeiro quanto o que está escrito, tão verdadeiro quanto Cristo morreu e ressuscitou, aquele que acredita nesta carta e a carrega consigo não pode sofrer nenhum dano corporal. Eu conjuro todos os fuzis e armas ao Deus vivo, Pai, Filho e Espirito Santo, bem como a todos os santos, que hoje nenhum rifle mortifero pode me ferir ou matar. Deus o Pai esteja comigo, Deus o Filho esteja comigo e Deus o Espirito Santo esteja entre todas as balas. Amém.

$O$ conde Felipe de Flandres, que tinha um cavaleiro e queria deixar cortar-lhe a cabeça por causa de um roubo, não podia fazê-lo através de seu carrasco, pois ele não podia nem feri-lo nem decapitá-lo; isso despertou grande admiração no conde e em todos os presentes. $O$ conde deixou que lhe inquirissem a respeito e fez com que ele confessasse como isso acontecera, ao que ele lhe concedeu a vida ${ }^{22}$, e o cavaleiro lhe mostrou esta carta com as seguintes letras

\section{$\boldsymbol{B}+\boldsymbol{K}+\boldsymbol{B}+\boldsymbol{D}+\boldsymbol{B}+\boldsymbol{W}+\boldsymbol{K}$}

Todos os seus servos ficaram muito surpresos e o conde imediatamente deixou fazer uma cópia da carta. Se o nariz de alguém sangra ou se fere, basta colocar esta carta sobre ele, então o sangue logo estancará. - Ou, quem não acredita nisso, este escreva as letras mencionadas em uma faca e apunhale um animal, ele não sangrará.

Bin. $\dagger$ Vertus. $\dagger$ Bertus. $\dagger$ Nomet. $\dagger$ Sibusch. $\dagger$ Muranemet. $\dagger$

Jesus. $\dagger$ Maria. $\dagger$ Joseph. $\dagger$

Esta carta poderosa e salutar para todas as pessoas foi encontrada no ano de 805 na tumba de nosso Salvador. O imperador Carlos a recebeu remetida pelo papa da França, que a deixou imprimir em uma placa com letras douradas. Quem ouve esta oração diariamente, a ora ou a ouve sendo orada e com isso une o Pai-Nosso do sofrimento de Jesus, não morrerá de morte não natural, nem morrerá envenenado.

${ }^{22}$ No sentido de ter poupado o cavaleiro da sentença de morte. 
Uma mulher em dores de parto facilmente dará a luz se o homem colocar a carta no lado direito do recém-nascido da mãe e el ${ }^{23}$ será libertado de todo o infortúnio. Também quem trouxer esta oração consigo não será acometido por nenhuma doença. Quem levar esta oração de casa em casa será abençoado, quem zombar dela será amaldiçoado.

Também a casa, na qual ela ${ }^{24}$ se encontra, não será atingida por tempestades. E, por último, quem ora esta oração ou a ouve sendo orada, verá 3 dias antes de seu fim um sinal do céu.

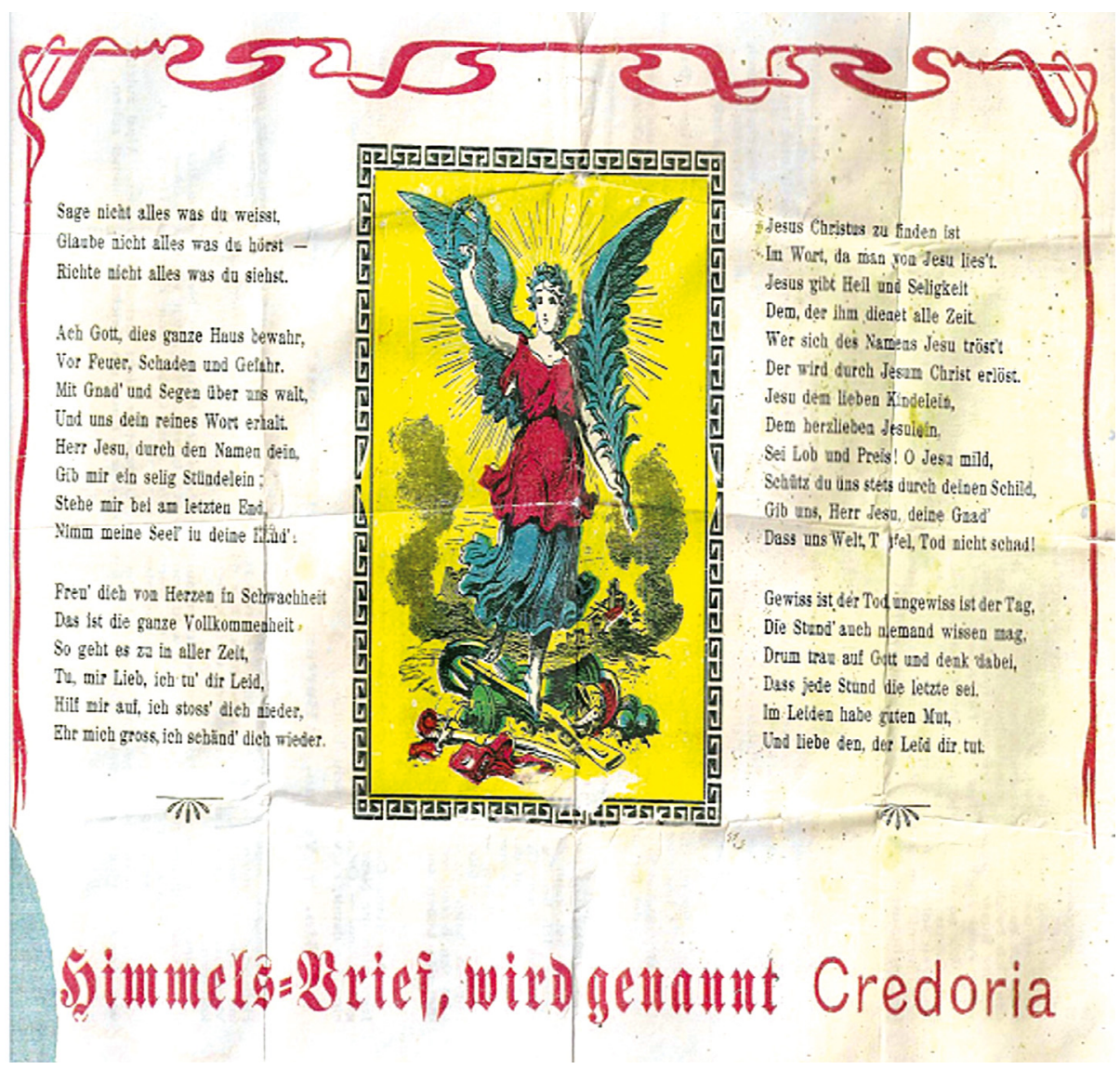

${ }^{23} \mathrm{O}$ bebê.

${ }^{24}$ A Carta do Céu. 


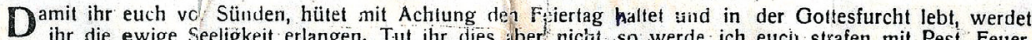
ihr die ewige Seeligkeit erlangen. Tut ihr dies :ber nichin, so werde ich eucit strafen mit Pest, Feuer, Hunger, Krieg und mit meiner errnsten Strafe. Ich worde aussetzen eineın König wider den andern, ein Herr wider cias andere, die Tochter wider die Mutter, Einen Bruder wider den andern, und ich werde alsdann meine Hand von euch wegnehmen. Wegen etirer Ungerechtigkeit werde ich zweischneidige Schwerter ergreifen und euch vertilgen hernach mit Donner und Blitz auf Erde herabfaliren, damit ihr erkennet meinen Zorn und meine götlliche Gerechtigkeit, weil ihr des Sonntags arbeitet. Aus väterlicher Liebe zu euch, habe ich euch bisher verschont, sonst wäret ich schon längst, wegen eurer Ungerechtigkeit verdammet wor. den; ich befehle euch. sowohl Jung als Alt, dass iht fleissig zur Kirche geht, und eure Sünden bereuet. Bei der Busse müssel ihr vor-und nachher nicht eure Nächsten beleidigen, auch kein falsches Zeugnis wider eurer Nächsten abgeben. Hütet euch vor Unterdrückung der Armen, sondern helfet den Dürstigen.

Wer an diesen. Brief nich glaubt, der soll nie die ewige Selligkeit erlangell, wer ihn aber bei sich trägt und andern zum Lesen giebt, der mag Sünden auf sich haben wie Sterme am Himmel oder Sandkörner am Meer, so sollen ihım seine Sünden vergeben werden; wer aber, voul diesem Briefe hört, ihn nicht erwirbet und ihn nicht in seinem Hause hat, der hat keinen Segen. Wer ihn aber nicht zt -esen oder Abschrei. ben giebt. der soll, verdanmet werden. Zuletzt befeale ich euch, dass ibr meir, Jebote haltet, wie sie

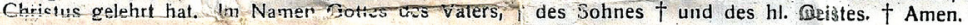

\section{Wer diesen Segen bei sich trägt}

wird von einem geladenen Gewehr keinen Schaden leiden, denn es sind Wörte, die das Göttliche bekräftigen und wofür man sich zu fürchten. Dieser Brief schützt vor allem Geschoss, Diebe, Feinde und allen Beschwerlichkeiten. Durch die folgende Wörte und den Namen unseres Herrn Jesu Christi und mit Gott können alle Beschwerden. Schwerter, Gewehre und allis Geschütz besprochen werden:

1) Stehet still alle sichtbaren und unsichtbaren Gewehre, damit ihr nicht auf mich losgehet, durch die Taufe unstres Herın Jesu Christi, der von Johannes im Fluss Jordan getauft vorden ist.

2) Stehet still alle sichibaren und unsichibaren Gevehre. damit ihr nich auf mich losgehet, durch den Befehl des heiligen-Oeistes.

3) Stehet still alle sichtbaren und unsichtbarer: Gewehre, durch die Angst unseres Herrn Jesu Christi, we!cher dich und mich erschaffen hat.

4) Siehet still alle sichtbaren und unsichibaren Gewehre und Waffen durch jie heilige Taufe dessen, der für unil gestorben. Märtyrer, als mächtiger Gott sei uns gnädig! In Namen Gottes des Vaters, $f$ unu des Sohnes $\dagger$ unâ des heiliget Geistes + Amen.

Wer vielleicht vorstehenden Wörte , keinen Glauben beimessen will, der darf sie nur auf einen 'Zettel schreiben und denseben einem Hund um den Hals hängen, sodann nach ihm schiessen, ond er wird ihn standen ist. kann der welcher an diesen Brief glaubt und ihn bei sich tiägt. keinen leiblichen Schaden leiden. Ich beschwöre alle. Gewehre und Waffen bei dem lebendigen Gott des Vaters, $†$ des Sohnes $t$ und des leiligen Geisles $\dagger$ sowie aller Heiligen, dass mich heute kein tötliches Gewehr verwunden noch töten kann. Gott der. Vater sei mit mir, Gott der Sohn sei-mit mir und Gott der-hl. Geist sei zwichen allen Kug ili. Amen,

G. If MFllipn von Flandern, der einen Ritter hatte, und diesem eines Diebstahls wegen dem Kopi ab. hauen lassen wolte, vernochte es duich seinen Scharfrichter nicht, denn er konnte ihn weder verwi nden noch enthaupten; dies erregte grosse Verwundering bei dem Grafen und allen Anwesenden. Der Giraf liess ihn hierauf vorforde⿰ und, brachte ihw' zum Geständnis, mit welchen Dingen es zuginge worauf er $\mathrm{ihm}$ das Leben schenkte, und der Ritter ihm diesen Brief mit folgenden Buchstaben vorzeigte.

\section{$\mathbf{B}+\mathbf{K}+\mathbf{B}+\mathbf{D}+\mathbf{B}+\mathbf{W}+\mathbf{K}$}

Alle seine Diener verwanderten sich sehr und der Graf liess diesen Brief sogleich abschreiben. Wenn Jemanden die Nase blutet oder verwundet wird, der lege nur diesen Btief darauf, so wird sich das Blut gleit stillen. - Oder, wer es nicht glaubt, der schreibe vorstehende Buchstaben auf em Messer und steche ein Tier damit, es wird nicht bluten.

Bin. $\dagger$ Vertus. Bertus. .. Nomet + Sibusch. $\dagger$ Muranemet. $\dagger$ Jesus. $\dagger$ Niaria. $\dagger$ Jaseph. $\dagger$

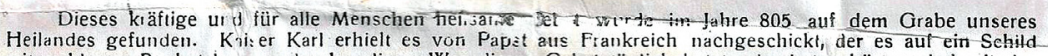
mit goldenen. Buchstabrı ausdrucken liess. Wer dieaes Gebet täglich betet oder beten hört und damit das Vaterunser aus Jesu Leiden verbindet, wird keinen unnatürlichen Tod sterben, auch sicht durch Gift umkommen.

Eine Frau in Kindesnöten wird leicht entbunden, wenn der Maun des Neugeborene der Mutter zur rechten Seite dieses Briefes legt, und es wird von Unglück befreit sein. Auch wird, wer dieses Gebet bei sich trägt, von keiner Krankheit angefochtet werden. Wer dies Gebet von Haus zu Haus trägt. wird gesegnet, wer es verspottet wird verflucht werden:

Auch wird das Haus, worin er sich befindet. von Ungewitter nicht getroffen werden. Und zuletzt, wer dies Gebet betet oder beten hört, wird 3 Tage vor seinem Ende ein Zeichen vom Himmel sehen.

Fig. 1 e 2: Himmels-Brief Credoria, exemplar de descendentes pomeranos em Pelotas (RS). Fonte: MALTZAHN, 2011, p. 141s.

Diferentes versões impressas da Carta do Céu ou da Carta de Proteção contêm a figura de anjos, com destaque para o arcanjo Miguel, pisando sobre diferentes 
tipos de armamento (veja Fig. 1) ou flutuando com uma trombeta em uma das mãos e ramos verdes na outra e cercado por armamentos. ${ }^{25}$ Desta forma, esse documento adquiria, independentemente do grau de compreensão do conteúdo por parte de seus portadores, uma função de proteção dentro do cultivo de uma religiosidade popular.

O nome Credoria, em outras versões também Gredoria ou Grodoria, possivelmente é uma reformulação popular da expressão latina Deo gloria ou da palavra Credo, como provavelmente era compreendida entre descendentes de pomeranos no Brasil. Isso é possível de ser deduzido de uma versão traduzida da carta para o português, encontrada em Pelotas (RS), onde a carta é chamada de Mensagem (Carta) Celeste - (chamada Credo). ${ }^{26}$

As admoestações de guardar o domingo e de não dar falso testemunho contra o próximo são claras referências ao Decálogo - terceiro e oitavo mandamentos. Em outras versões faz-se referência também ao segundo e quarto mandamentos. ${ }^{27}$ Outras citações bíblicas também são parafraseadas ${ }^{28}$ ou citam versos de hinos ou canções para crianças presentes em hinários trazidos pelos imigrantes e utilizados por seus descendentes no Brasil. ${ }^{29}$ Em uma das versões da Carta de Proteção é ainda citada uma oração, cujo final é idêntico a uma oração do assim chamado Evangelisches Hausbuch, um devocionário editado pelo Comitê Eclesiástico Evangélico Alemão para igrejas evangélicas na diáspora. ${ }^{30}$ Além disso, segundo Stübe, as orações que introduzem ou encerram alguns exemplares das Cartas do Céu ou Cartas de Proteção seriam variações rimadas da oração do Pai-Nosso e de provérbios cristãos ou de

${ }^{25}$ Veja a versão da Carta do Céu encontrada no Espírito Santo. HIMMELSBRIEF GREDORIA. Impressa na Papelaria Alexandre Ribeiro, Rio de Janeiro. Sem indicação do ano. Folha A4, 1 folha, 1 página. Fonte concedida gentilmente pela Dra. Claudete Beise Ulrich. Compare com a versão praticamente idêntica encontrada na Biblioteca da Universidade de Göttingen, na Alemanha: HIMMELS-BRIEF, welcher mit güldenen Buchstaben geschrieben und ist zu sehen in der Michaelis Kirche zu St. German, wird genannt Gredoria, allwo der Brief über der Taufe schwebt. [Carta do Céu, que é escrita com letras douradas e pode ser vista na Igreja de São Miguel de São Germano, é chamada Gredoria, onde a carta paira acima d[a pia do] batismo]. Medidas do documento: $41 \mathrm{~cm} \mathrm{x} \mathrm{341/2} \mathrm{cm,} 1$ folha, 1 página. Rro 65 . Niedersächsische Staats- und Universitätsbibliothek Göttingen, Número de Inventário DD97 D 1. A Carta do Céu do tipo Gredoria era amplamente utilizada como gravura emoldurada no norte da Alemanha. Ela provinha da cidade de Neuruppin, também localizada no norte da Alemanha. STÜBE, R. Gredoria. In: HOFFMANKRAYER, E.; BÄCHTOLD-STÄUBLI, Hanns (Hrg.). Handwörterbuch des Deutschen Aberglaubens [Dicionário de superstição alemã]. Berlin; Leipzig: Walter de Gruyter, 1930/1931. v. 3, p. 1.126s.

${ }^{26}$ Sem indicação do local de impressão, 1 folha, 2 páginas. Fotografia. In: MALTZAHN, 2011, p. 143s.

27 HIMMELSBRIEF GREDORIA. Impressa na Papelaria Alexandre Ribeiro, Rio de Janeiro. Veja também SCHUTZBRIEF. Sem indicação do local de impressão. Folha A4. 1 folha, 2 páginas. Arquivo privado do pastor Nelso Weingärtner.

${ }^{28}$ HIMMELSBRIEF. Sem indicação do local de impressão. Folha A4, 2 folhas, 3 páginas. Arquivo privado do pastor Nelso Weingärtner; HAUS- UND SCHUTZBRIEF. Neu Ruppin: Gustav Kuhn. 1 folha, 1 página, Fotografia. In: SEIBEL, Ivan. Imigrante no século do isolamento/1870-1970. São Leopoldo: Traço, 2010. p. 332.

${ }^{29}$ HAUS- UND SCHUTZBRIEF. In: SEIBEL, 2010, p. 332.

${ }^{30}$ HAUS- UND SCHUTZBRIEF. In: SEIBEL, 2010, p. 332, compare com: Gebete in Todesnöten $n^{\circ} 1$. DEUTSCHER EVANGELISCHER KIRCHENAUSSCHUSS (Hrg.). Evangelisches Hausbuch für die Deutschen im Ausland [Devocionário [Livro de Casa] Evangélico para alemães no exterior]. Berlin: Mittler und Sohn, 1912. p. 76. 
conteúdo moral. ${ }^{31}$ No exemplar aqui analisado (Fig. 1 e 2), a oração diária da carta juntamente com a oração do Pai-Nosso garantiria proteção contra uma morte não natural ou contra uma morte por envenenamento. Todas as referências bíblicas, de devocionários, hinários e provérbios, juntamente com a fórmula trinitária, Em nome do Pai, do Filho e do Espírito Santo, amém, acompanhada do sinal da cruz (†) - o que indica uma possível prática de fazer o sinal da cruz durante a leitura da carta -, contribuíam para que imigrantes e seus descendentes não encontrassem contradição entre o conteúdo das Cartas do Céu ou Cartas de Proteção e sua fé evangélico-luterana. Elas também facilitavam a memorização e tratavam de assuntos que lhes eram de vital importância: a redenção e salvação por meio de Jesus Cristo, a transitoriedade da vida, a ajuda de Deus nas dificuldades, a vida eterna, a proteção contra os males do mundo, do diabo e da morte, bem como contra danos causados por incêndios, perigos e armas.

$\mathrm{O}$ não cumprimento dos mandamentos e das exigências morais, segundo o conteúdo dos diferentes exemplares de Cartas do Céu ou Cartas de Proteção, acarretaria peste, fome, guerra e castigos para as pessoas. Quem não acreditasse em seu conteúdo era inclusive ameaçado com maldição e perdição eternas. Isso causava medo nas pessoas e consequentemente aumentava sua disseminação. Já o porte da carta garantiria proteção contra catástrofes naturais, estancamento de sangramento, um parto fácil e um sinal do céu três dias antes da morte da pessoa que a portasse. Por causa disso, as pessoas carregavam a carta dobrada junto a seu corpo. Os sinais de dobradura ainda podem ser reconhecidos nas Fig. 1 e 2, bem como em outros exemplares da carta encontrados entre descendentes de imigrantes no Brasil. ${ }^{32}$ Quem carregasse a carta consigo, a lesse para outros e multiplicasse seu conteúdo por meio de cópias teria a garantia do perdão de seus pecados e a bênção de Deus. Por essa razão existem inúmeros exemplares da carta copiados à mão, com todos os erros ortográficos e gramaticais oriundos dessa reprodução. ${ }^{33}$ Mas por se tratar de um conteúdo sagrado, com um suposto efeito mágico, quem copiava a carta não corrigia eventuais erros, e sim os reproduzia literalmente. ${ }^{34}$

A eficácia das Cartas do Céu reside na fé no suposto poder mágico atribuído ao seu texto ou palavras e no uso de um conjunto de letras, palavras ou sílabas aparentemente sem sentido - no exemplar analisado as misteriosas letras: $B \dagger K \dagger B \dagger D \dagger B \dagger W$ $\uparrow K$, bem como o conjunto de palavras: Bin. $\dagger$ Vertus. $\dagger$ Bertus. $\dagger$ Nomet. $\dagger$ Sibusch. Mur Muranemet. $\dagger$ Jesus. $\dagger$ Maria. $\dagger$ Joseph. $\dagger$. Seu conteúdo mistura passagens bíblicas e a fórmula trinitária com textos mágicos pagãos, como, por exemplo, amuletos, fórmulas de encantamento, bênçãos sobre animais ou sobre o sangue, letras enigmáticas, o convite para provar seu poder em animais e ditos mágicos. Trata-se de uma composição que reúne textos originalmente independentes emoldurados por uma introdução, uma fórmula de encantamento ou uma lenda, que consequentemente explicam a utilização e a eficácia da fórmula. A isso podem ser acrescentadas informações históricas sobre

${ }^{31}$ STÜBE, 1918 , p. 7.

${ }^{32}$ HIMMELSBRIEF. Arquivo privado do pastor Nelso Weingärtner.

${ }^{33}$ SCHUTZBRIEF. Cópia à mão. Folha A4, papel com linhas. 2 folhas, 4 páginas.

${ }^{34}$ STÜBE, 1918, p. 44s. 
a origem, o lugar e o ano de seu aparecimento. ${ }^{35}$ As diferentes bênçãos e fórmulas de encantamento contêm elementos de religiões populares antigas presentes na literatura da Antiguidade, fórmulas mágicas de origem germânica da época medieval e tradições cristãs que lhes foram acrescentadas no início do período moderno. ${ }^{36}$

Apesar de o exemplar aqui analisado ser intitulado de Credoria, ele contém elementos que o identificam com o tipo de Carta do Céu conhecido como Holstein. Essa variação teria aparecido, segundo informações fornecidas em outros exemplares da Carta do Céu do tipo Holstein ${ }^{37}$, no ano de 1724. Ela teria sido copiada no ano de 1791 e menciona a localidade de Holstein. Essa variação ficou conhecida como Carta do Céu da Primeira Guerra Mundial, pois teria sido utilizada por muitos soldados durante essa guerra. ${ }^{38}$ As partes originalmente independentes, que lhe foram agregadas ao longo de sua história traditiva, serão brevemente analisadas a seguir:

1. O Amuleto do Conde ou Bênção do Conde Felipe: originalmente tratava-se de uma Bênção sobre as armas com um amuleto de letras de caráter mágico, utilizada por comerciantes como proteção contra todo tipo de feridas durante suas viagens. Sua origem pode ser rastreada até o século XV e ela apareceu pela primeira vez em ligação com uma Carta do Céu nos anos de 1523 e 1546 e em um folheto da cidade alemã de Colônia no ano de 1604. De acordo com a legenda, o conde Felipe teria ordenado a decapitação de um de seus servos, mas nenhum dano lhe podia ser desferido, por ele supostamente portar uma proteção especial. Sendo assim, o conde teria prometido poupar sua vida, caso ele revelasse seu segredo. Assim o servo lhe mostrou um bilhete com letras e números aparentemente sem sentido, que teriam um poder mágico de proteger seu portador de qualquer ferida, poder natural (como fogo, tempestade) e calúnia, bem como o poder de estancar sangramentos e possibilitar um melhor trabalho de parto às mulheres. ${ }^{39}$

2. O Provérbio do Monte das Oliveiras: originalmente outra Bênção sobre as armas ou um dito de proteção contra ferimentos que pudessem ser causados por espada ou armas. Ela continha a fórmula: "assim como Cristo esteve parado no Monte das Oliveiras, assim todas as armas deverão ficar paradas" ${ }^{40}$. O antigo provérbio continha também indicações sobre a forma como sua eficácia poderia ser testada: a fórmula deveria ser amarrada no pescoço de um cachorro, em seguida alguém poderia atirar nele; ou a fórmula poderia ser escrita sobre uma espada ou arma e alguém poderia tentar ferir um animal com ela. À fórmula ainda se acrescentava nomes de livros mágicos - como Bertus, Nomet, Sibusch, Muranemet - e da família sagrada - Jesus,

\footnotetext{
35 STÜBE, 1918, p. 6s, 29.

${ }^{36}$ BAUER, Magisch-sympathetischer Hausschatz, 1979, p. 174.

37 Como o exemplar da CARTA DO CÉU. In: DIETERICH, 1901, p. 9s.

38 STÜBE, R. Holsteiner-Typus. In: HOFFMAN-KRAYER; BÄCHTOLD-STÄUBLI (Hrg.), 1931/1932, v. 4, p. 261; STÜBE, 1931/1932, p. 21s; STÜBE, 1918, p. 7s, 10.

39 STÜBE, R. Grafenamullet. In: HOFFMAN-KRAYER; BÄCHTOLD-STÄUBLI (Hrg.), 1930/1931, v. 3, p. $1.111 \mathrm{~s}$.

40 STÜBE, R. Oelbergspruch. In: HOFFMAN-KRAYER, E.; BÄCHTOLD-STÄUBLI, Hanns (Hrg.). Handwörterbuch des Deutschen Aberglaubens [Dicionário de superstição alemã]. Berlin; Leipzig: Walter de Gruyter, 1934/1935. v. 6, p. 1.246s.
} 
Maria e José. Em alguns exemplares, como o aqui analisado, faz-se ainda menção do batismo de Jesus em ligação com a paralisação de armas ou da água.

3. A Oração do Imperador Carlos, o Grande: tratava-se de uma oração encontrada em livros mágicos medievais, como, por exemplo, no livreto Colomanus, que teria sido enviada por Deus pelo abade Colomanus ao seu pai, o rei da Ibéria. Como o rei inicialmente não teria acreditado no caráter protetivo desse documento, ele ordenou que seu poder fosse testado em um criminoso, a quem nem espada, nem fogo ou veneno podiam causar dano. Sendo assim, o rei teria ordenado a multiplicação dessa oração e o papa Leo III teria enviado uma cópia da carta contendo a oração ao imperador Carlos, o Grande (768-814). Esse teria mandado pintar seu conteúdo em um escudo com letras douradas. De acordo com outra versão da história, originária do século XV ou XVI em Brieg, atualmente no território da Polônia, essa bênção teria sido enviada do céu ao imperador Carlos por meio do papa Leo III. O papa Leo teria ainda enviado uma oração idêntica a essa ao seu irmão Carolo em um devocionário católico. ${ }^{41}$

No exemplar analisado é possível reconhecer a presença dessas diferentes partes, o que nos leva a concluir que, apesar da intitulação Credoria, estamos na verdade lidando com um exemplar de Carta do Céu do tipo Holstein. ${ }^{42}$

\section{Considerações finais}

Cartas do Céu enquadram-se no gênero literário da revelação escrita de Deus, cuja tradição provém da Antiguidade e é adotada também no helenismo. Seu conteúdo e sua propagação comprovam, apesar do descrédito que esse documento sofreu por parte da igreja, que sua origem e seu desenvolvimento aconteceram em âmbito eclesial.

Devido ao seu conteúdo ameaçador, seu caráter misterioso e seu efeito mágico, Cartas do Céu alcançaram grande aceitação por parte da população, mas também entre o clero. Isso contribuiu para sua rápida multiplicação por meio de inúmeras cópias impressas e à mão. Principalmente durante conflitos armados e guerras, mas também diante de outras dificuldades, para as quais as pessoas necessitavam de algo concreto para sua proteção, elas adquiriam maior importância. Isso é comprovado pelo uso mais intenso dessas fontes durante as guerras, em diferentes revoluções e batalhas, principalmente na Europa, mas também no período de colonização no Brasil, quando os imigrantes e seus descendentes careciam de estruturas que lhes garantissem o acesso à assistência médica, principalmente a parteiras, e proteção contra os perigos

${ }^{41}$ STÜBE, R. Karl-Segen (Kaiser). In: HOFFMAN-KRAYER; BÄCHTOLD-STÄUBLI (Hrg.), 1931/1932, v. 4 , p. $1.006 \mathrm{~s}$.

${ }^{42}$ Esse tipo de Carta do Céu possui, por sua vez, grande semelhança com um exemplar de Carta de Proteção encontrado em Santa Catarina. Para uma comparação entre os diferentes tipos de Cartas do Céu e Cartas de Proteção encontrados entre descendentes pomeranos do Espírito Santo, Santa Catarina e Rio Grande do Sul, veja JANKE, Scheila Roberta. Die Religiosität der Pommern in Brasilien. Eine Studie zu den pommerschen Einwanderern und deren Nachkommen im 19. und 20. Jahrhundert. [A Religiosidade dos pomeranos no Brasil. Um estudo sobre os imigrantes pomeranos e seus descendentes nos séculos XIX e XX]. Göttingen: Universitätsverlag, 2019. p. 409-433. 
na mata. Como as cartas misturavam conteúdo mágico e fórmulas de encantamento com conteúdo cristão - orações, textos bíblicos, hinos, fórmula trinitária, sinal da cruz e imagens de anjos -, as pessoas não viam nenhuma contradição entre o uso de Cartas do Céu e outras fontes de fé que detinham o aval da igreja: Bíblia, hinários e devocionários.

A análise de um dos exemplares da Carta do Céu permitiu, por fim, fazer o reconhecimento das diferentes partes que foram agregadas ao longo dos séculos ao conteúdo original da carta, fazendo com que ela, dessa forma, adquirisse um caráter ainda mais ameaçador, mágico e eficaz como fonte de fé e de proteção.

\section{Referências}

BAHIA, Joana. O tiro da bruxa. Identidade, magia e religião na imigração alemã. Rio de Janeiro: Garamond, 2011.

BAUER, Wolfgang. Magisch-sympathetischer Hausschatz oder Die offenbarten Geheimnisse der natürlichen Magie nebst Zauberformeln, Heil-Sprüchen und Schutzsegen wider allerlei Anfechtungen. In: 6./ 7. Buch Moses. Sein wahrer Wert und was das Volk darin sucht. Einleitung und Bildkommentare von Wolfgang Bauer. Berlin: Karin Kramer, 1979. p. 31-225.

BAUER, Wolfgang. Was hat man von dem Volksglauben und der Volksmedizin zu halten? In: 6./ 7. Buch Moses. Sein wahrer Wert und was das Volk darin sucht. Einleitung und Bildkommentare von Wolfgang Bauer. Berlin: Karin Kramer, 1979. p. 1-30.

BECKERT, Hans Günther; NAIL, Norbert. Der alte Gasthof zum Schützenpfuhl in Marburg. Mit einem Beitrag über „Himmelsbrief“. Marburg: Magistrat der Stadt Marburg, 2008.

DEUTSCHER EVANGELISCHER KIRCHENAUSSCHUSS (Org.). Evangelisches Hausbuch für die Deutschen im Ausland. Berlin: Mittler und Sohn, 1912.

DIETERICH, Albrecht. Himmelsbrief. In: Blätter für Hessische Volkskunde, Hrg. im Auftrag der Vereinigung für Hessische Volkskunde, n. 3, ano III, p. 9-12, 1901.

HAUS- UND SCHUTZBRIEF. Neu Ruppin: Gustav Kuhn. 1 folha, 1 página, Fotografia. In: SEIBEL, Ivan. Imigrante no século do isolamento/1870-1970. São Leopoldo: Traço, 2010. p. 332. HAUS-, SCHUTZ- UND HIMMELSBRIEF. In: Magisch-sympathetischer Hausschatz oder Die offenbarten Geheimnisse der natürlichen Magie nebst Zauberformeln, Heil-Sprüchen und Schutzsegen wider allerlei Anfechtungen. In: 6./ 7. Buch Moses. Einleitung und Bildkommentare von Wolfgang Bauer. Berlin: Karin Kramer, 1979. p. 181-183.

HIMMELSBRIEF. In: DIETERICH, Albrecht. Himmelsbrief. In: Blätter für Hessische Volkskunde, Hrg. im Auftrag der Vereinigung für Hessische Volkskunde, n. 3, ano III, p. 9-10, 1901. HIMMELSBRIEF. Sem indicação do local de impressão. Folha A4, 2 folhas, 3 páginas. Arquivo privado do pastor Nelso Weingärtner.

HIMMELSBRIEF GREDORIA. Impresso na Papelaria Alexandre Ribeiro, Rio de Janeiro. Sem indicação do ano. Folha A4, 1 folha, 1 página. Fonte concedida gentilmente pela Dra . Claudete Beise Ulrich.

HIMMELS-BRIEF welcher mit güldenen Buchstaben geschrieben und ist zu sehen in der Michaelis Kirche zu St. German, wird genannt Gredoria, ca. 1720. Medidas do documento: $41 \mathrm{~cm} \times 34 \frac{1}{2} \mathrm{~cm}$, 1 folha, 1 página. Rro 65 . Niedersächsische Staats- und Universitätsbibliothek Göttingen. Numero de inventário DD97 D 1.

HIMMELS-BRIEF WIRD GENANNT CREDORIA. Sem indicação do local de impressão. 1 folha, 2 páginas. Fotografia. In: MALTZAHN, Gislaine Maria. Familia, ritual e ciclos de vida. 
Estudo Etnográfico sobre narrativas pomeranas em Pelotas (RS). Pelotas: Universidade Federal de Pelotas, 2011. p. 141-142.

JANKE, Scheila Roberta. Die Religiosität der Pommern in Brasilien. Eine Studie zu den pommerschen Einwanderern und deren Nachkommen im 19. und 20. Jahrhundert. Göttingen: Universitätsverlag, 2019.

LUTHER, Martin. Ob kriegsleutte auch ynn seligem stande seyn künden. In: D. Martin Luthers Werke. Weimar: Böhlau, 1897. v. 19, p. 623-662.

MENSAGEM (Carta) celeste (chamada Credo). Sem indicação do local de impressão. 1 folha, 2 páginas. Fotografia. In: MALTZAHN, Gislaine Maria. Familia, ritual e ciclos de vida. Estudo Etnográfico sobre narrativas pomeranas em Pelotas (RS). Pelotas: Universidade Federal de Pelotas, 2011. p. 143-144.

RÖHRICH, L. Himmelsbriefe. In: GALLING, Kurt et al. (Hrg.). Die Religion in Geschichte und Gegenwart. Handwörterbuch für Theologie und Religionswissenschaft. 3. ed. Tübingen: Mohr (Paul Siebeck), 1959. v. 3, p. 338-339.

SCHUTZBRIEF. Cópia a mão. Folha A4, papel com linhas. 2 folhas, 4 páginas.

SCHUTZBRIEF. Sem indicação do local de impressão. Folha A4. 1 folha, 2 páginas. Arquivo privado do pastor Nelso Weingärtner.

STÜBE, R. Der Himmelsbrief. Ein Beitrag zur allgemeinen Religionsgeschichte. Tübingen: Mohr (Paul Siebeck), 1918.

STÜBE, R. Grafenamullet. In: HOFFMAN-KRAYER, E.; BÄCHTOLD-STÄUBLI, Hanns (Hrg.). Handwörterbuch des Deutschen Aberglaubens. Berlin; Leipzig: Walter de Gruyter, 1930/1931. v. 3, p. 1.111-1.112.

STÜBE, R. Gredoria. In: HOFFMAN-KRAYER, E.; BÄCHTOLD-STÄUBLI, Hanns (Hrg.). Handwörterbuch des Deutschen Aberglaubens. Berlin; Leipzig: Walter de Gruyter, 1930/1931. v. 3, p. 1.126-1.127.

STÜBE, R. Himmelsbrief. In: HOFFMAN-KRAYER, E.; BÄCHTOLD-STÄUBLI, Hanns (Hrg.). Handwörterbuch des Deutschen Aberglaubens. Berlin; Leipzig: Walter de Gruyter, 1931/1932. v. 4, p. 21-27.

STÜBE, R. Holsteiner-Typus. In: HOFFMAN-KRAYER, E.; BÄCHTOLD-STÄUBLI, Hanns (Hrg.). Handwörterbuch des Deutschen Aberglaubens. Berlin; Leipzig: Walter de Gruyter, 1931/1932. v. 4, p. 261.

STÜBE, R. Karl-Segen (Kaiser). In: HOFFMAN-KRAYER, E.; BÄCHTOLD-STÄUBLI, Hanns (Hrg.). Handwörterbuch des Deutschen Aberglaubens. Berlin; Leipzig: Walter de Gruyter, 1931/1932. v. 4, p. 1.006-1.007.

STÜBE, R. Oelbergspruch. In: HOFFMAN-KRAYER, E.; BÄCHTOLD-STÄUBLI, Hanns (Hrg.). Handwörterbuch des Deutschen Aberglaubens. Berlin; Leipzig: Walter de Gruyter, 1934/1935. v. 6, p. 1.246-1.247.

STÜBE, R. Sonntagsbrief. In: HOFFMAN-KRAYER, E.; BÄCHTOLD-STÄUBLI, Hanns (Hrg.). Handwörterbuch des Deutschen Aberglaubens. Berlin; Leipzig: Walter de Gruyter, 1936/1937. v. 8, p. 99-104. 